\title{
Hand Hygiene Compliance in a Medical-Surgical Intensive Care Unit in La Habana
}

\author{
Humberto Guanche Garcell ${ }^{*}$, Luis Gonzalez Alvarez' ${ }^{1}$ Anayka González Valdés ${ }^{1}$, Katerine Cardenas \\ Goulet $^{1}$, Gloria Fresneda Septiem ${ }^{1}$, Francisco Gutierrez García ${ }^{1}$
}

${ }^{1}$ Hospital Epidemiology Department, Hospital Joaquín Albarrán, La Habana, Cuba

*Corresponding Author: Humberto Guanche Garcell, MD, MPH, Hospital Epidemiology Department, Hosp. Joaquín Albarran, 43 Ave, no 8411 \% 84 y 84a, Marianao 14, La Habana, Cuba. Tel: +53-72674367,

Email: guanche@infomed.sld.cu

Received May 8, 2019; Accepted July 28, 2019; Online Published August 26, 2019

\begin{abstract}
Background: Hand hygiene plays a key role in the prevention of healthcare-associated infection in critical patients.

Objective: The current study aimed to evaluate compliance with hand hygiene practices.

Methods: An observational and descriptive study was carried out in a 35-bed medical-surgical critical care unit in La Habana (Cuba) from January 2017 to December 2018. The observational method recommended by the World Health Organization (WHO) was used.

Results: Overall compliance was 34.2\% (5516/16125), with better compliance among physicians (39\%) compared with nurses (31.4\%) and ancillary staff (19.5\%). Better compliance was observed after patient contact $(65.7 \%)$ and after contact with patients' surroundings $(42.0 \%)$ in comparison with greater focus on patient safety as before patient contact $(23.3 \%)$ and before an aseptic task (11.4\%). Hand washing was performed more frequently than hand rubs.

Conclusion: Compliance with hand hygiene practices is low and no improvement in compliance was observed during the study period. This practice is related to the high risk of transmission of healthcare-related infections in critical patients and requires quality improvement interventions.
\end{abstract}

Keywords: Hand Hygiene, Compliance, Critical Care Unit, Medical-Surgical, La Habana

\section{Background}

Hand hygiene $(\mathrm{HH})$ compliance is a critical factor related to healthcare-associated infection transmission in healthcare facilities. ${ }^{1}$ This issue is more relevant in critical patients, for whom their characteristics, the intensive use of invasive procedures, plus non-compliance with infection control practices determine the level of risk of acquiring healthcare-associated infections. ${ }^{2-5}$

A recently published report described compliance rates from $7 \%$ to $49.6 \%$ in intensive care units using the observational methods recommended by the World Health Organization (WHO). ${ }^{2-5}$ Two studies conducted in emergency medical services reported very low compliance. ${ }^{6,7}$ One study that used the WHO method to evaluate ambulance services from 4 European countries and a second study that used video-assisted observation in a trauma resuscitation setting reported compliance rates of $15 \%$ and $7 \%$, respectively.

Limited data has been published about $\mathrm{HH}$ compliance in Cuban healthcare facilities..$^{8-10}$ The International Nosocomial Infection Control Consortium report provides data from medical-surgical intensive care units (ICU) in 19 countries, including data from a Cuban ICU. ${ }^{9}$ This report included data on $434 \mathrm{HH}$ opportunities, and the overall compliance increased from $44 \%$ to $76 \%$ (95\% CI 57.7-88.9; $P=0.002$ ).

The Joaquín Albarrán Hospital is a 300-bed secondary referral center that serves an adult population of Western Habana, Cuba (around 400000 inhabitants). Its 35-bed critical care unit provides clinical and surgical care, not including neurosurgery, cardiovascular surgery, complex trauma, or transplant surgeries.

\section{Objective}

The purpose of the current study was to measure compliance with $\mathrm{HH}$ practices among healthcare workers in this critical care unit.

\section{Methods}

This observational and descriptive study was carried out in a 35-bed medical-surgical critical care unit in La Habana, Cuba from January 2017 to December 2018. HH

Copyright (C) 2019 The Author(s). This is an open-access article distributed under the terms of the Creative Commons Attribution License (http:// creativecommons.org/licenses/by/4.0), which permits unrestricted use, distribution, and reproduction in any medium, provided the original work is properly cited. 
was monitored by trained infection control nurses based on the WHO recommendations and using the observation method. ${ }^{1}$ Observations were performed unobtrusively any day of the week for a maximum of 20 minutes per session, and $\mathrm{HH}$ moments (before patient contact, before performing an aseptic task, after exposure to body fluids, after patient contact, and after contact with patient's surroundings), staff category (nurse, physician, ancillary personnel), actions (hand rubs, hand washing, missed), and the product used (soap or alcohol) were recorded. All staff members assigned to patient care were observed, including nurses, physicians, and ancillary personnel.

The local infection control program included educational activities and feedback of compliance data to the staff as main components. The WHO goal for $\mathrm{HH}$ compliance (90\%) was used by the local program.

The study procedure was considered a component of the infection control program and did not interfere with patient care. For this reason, no ethical approval was required.

The number of actions performed (hand rubs or hand washing) divided by the number of opportunities and

Table 1. Hand Hygiene Compliance by Category and Moments in a Medical Surgical Critical Care Unit (by 100 Opportunities) (January 2017- December, 2018)

\begin{tabular}{llcc}
\hline & & \multicolumn{2}{c}{ Hand Hygiene } \\
\cline { 3 - 4 } Variable & & No. & $\%$ \\
\hline Category & & & \\
Physicians & 6857 & 2675 & 39.0 \\
Nurses & 8698 & 2730 & 31.4 \\
Ancillary Personnel & 570 & 111 & 19.5 \\
Hand hygiene moments & & & \\
Before patient contact & 5123 & 1193 & 23.3 \\
Before aseptic task & 2552 & 291 & 11.4 \\
\hline After exposure to body fluid & 2253 & 870 & 38.6 \\
\hline After patient contact & 2358 & 1550 & 65.7 \\
\hline $\begin{array}{l}\text { After contact with patient's } \\
\text { surroundings }\end{array}$ & 3839 & 1612 & 42.0 \\
\hline Total & 16125 & 5516 & 34.2 \\
\hline
\end{tabular}

expressed as a percentage of opportunities was calculated for each $\mathrm{HH}$ moment and category.

\section{Results}

During the study period, $16125 \mathrm{HH}$ opportunities were observed with a compliance rate of $34.2 \%$. The highest compliance was achieved by physicians (39\%) followed by nursing staff (31.4\%) and ancillary personnel (19.5\%). HH practices were performed after patient contact in $65.7 \%$, after body fluid exposure in $38.6 \%$, and after contact with a patient's surroundings in $42 \%$ of opportunities. The lowest compliance rates were achieved before patient contact (23.3\%) and before an aseptic task (11.4\%) (Table 1). A predominance of hand washing (83.6\%) and a low frequency of hand rub (16.4\%) were observed.

During the first quarter of the study period, compliance was $9.4 \%$; after that, it increased to between $28.5 \%$ and $39.9 \%$. No clear trend of improvement in $\mathrm{HH}$ compliance was observed during the period (Figure 1).

\section{Discussion}

Compliance with $\mathrm{HH}$ was low in the critical care unit with no evidence of improvement during the study period. Previously in this unit, no system to monitor $\mathrm{HH}$ quality had been implemented nor actions taken for improvement.

Low compliance with $\mathrm{HH}$ practices is a well-known finding in studies of healthcare facilities worldwide. ${ }^{1}$ There are three published studies about $\mathrm{HH}$ practices in Cuban healthcare facilities; 2 of them describe the results in critical care units with a compliance of over $50 \% .{ }^{9,10}$ The overall compliance observed in the current study was similar to the data in the literature..$^{2-7}$

There was no evidence of improvement during the study period, which could be related to various factors including deficiencies in staff education, irregular feedback, and loss of timely analysis of compliance data. Another factor, one relevant to improvement, is the weak leadership support to the infection control recommendations. ${ }^{1}$

Better compliance after patient contact, exposure to body fluid, and contact with the patient's surroundings is frequently revealed in many reports. ${ }^{2,3,5}$ This behavior that favors staff protection over patient safety constitutes

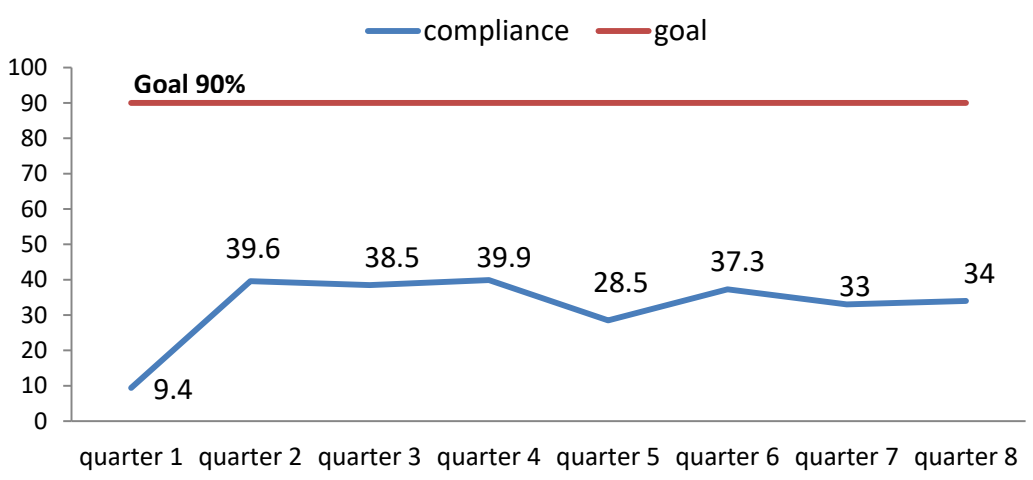

Figure 1. Hand Hygiene Compliance Per Quarter in a Critical Care Unit (by 100 Opportunities) (January, 2017-December, 2018). 


\section{Report Highlights}

\section{What Is Already Known?}

Hand hygiene is an essential practice for infection prevention. It is strongly related to the risk of healthcareassociated infections in healthcare facilities. The World Health Organization recommends its monitoring during the five moments described.

\section{What This Study Adds?}

This is the first paper regarding compliance with hand hygiene practices in a Cuban facility published in a peer review journal. It provides insight into the quality of hand hygiene and the need for quality improvement intervention in a limited resource country.

a significant risk to critical care patients and could be modified with quality improvement intervention focus in staff education.

The low frequency of hand rubs and the higher compliance among physicians in comparison with other categories are probably related to deficiencies in staff education and the availability of facilities to comply with hand rubs in patient-care areas (e.g., wall-mounted dispenser, pocket bottle).

\section{Conclusion}

$\mathrm{HH}$ practices in critical care units constitute a significant risk for healthcare-associated infections, and urgent action is required for improving patient and staff safety.

\section{Authors' Contributions}

HGG: Study design, training research team, analysis and draft; LGA: Study design, data collection, analysis and draft review; AGV: Study design, data collection, analysis and draft review; KCG: Study design, data collection, analysis and draft review; GFS: Study design, data collection, analysis and draft review; FGG: Study design, training research team, analysis and draft.

\section{Conflict of Interest Disclosures}

The authors declare that they have no conflicts of interest.

\section{Ethical Approval}

The paper was approved for publication by the facility's QPS committee.

\section{Acknowledgments}

The authors would like to thank Ms. Guillermina Fernandez Sanchez for her support during this research.

\section{References}

1. World Health Organization (WHO). WHO Guidelines on Hand Hygiene in Health Care: First Global Patient Safety Challenge Clean Care Is Safer Care. Geneva: WHO; 2009.

2. Stahmeyer JT, Lutze B, von Lengerke T, Chaberny IF, Krauth C. Hand hygiene in intensive care units: a matter of time? J Hosp Infect. 2017;95(4):338-343. doi:10.1016/j.jhin.2017.01.011.

3. Fonguh S, Uwineza A, Catry B, Simon A. Belgian hand hygiene campaigns in ICU, 2005-2015. Arch Public Health. 2016;74:47. doi:10.1186/s13690-016-0159-3.

4. Karaaslan A, Kepenekli Kadayifci E, Atici S, et al. Compliance of healthcare workers with hand hygiene practices in neonatal and pediatric intensive care units: overt observation. Interdiscip Perspect Infect Dis. 2014;2014:306478. doi:10.1155/2014/306478

5. Musu M, Lai A, Mereu NM, et al. Assessing hand hygiene compliance among healthcare workers in six Intensive Care Units. J Prev Med Hyg. 2017;58(3):E231-E237.

6. Vikke HS, Vittinghus $\mathrm{S}$, Giebner $\mathrm{M}$, et al. Compliance with hand hygiene in emergency medical services: an international observational study. Emerg Med J. 2019;36(3):171-175. doi:10.1136/emermed-2018-207872.

7. Haac B, Rock C, Harris AD, et al. Hand hygiene compliance in the setting of trauma resuscitation. Injury. 2017;48(1):165-170. doi:10.1016/j.injury.2016.08.004.

8. Suárez Tamayo S, Garcell HG, Cañas Ávila N, Maldonado Castillo G, Benitéz Martínez M. Adherencia a la realización del lavado de manos por el personal de enfermería de un hospital clínico quirúrgico de La Habana (Cuba). [Adherence to hand washing of nurses in a clinical surgical hospital of la Habana (Cuba)]. Hig Sanid Ambient. 2013;13(1):940-945.

9. Rosenthal VD, Pawar M, Leblebicioglu H, et al. Impact of the International Nosocomial Infection Control Consortium (INICC) multidimensional hand hygiene approach over 13 years in 51 cities of 19 limited-resource countries from Latin America, Asia, the Middle East, and Europe. Infect Control Hosp Epidemiol. 2013;34(4):415-423. doi:10.1086/669860.

10. Garcell HG, Nuñez Labrador L, Morales Pérez C, Fresneda Septiem G, Members of Provincial Infection Control Program. Compliance with Handwashing in Intensive Care Unit in University Hospitals of La Havana. Medicrit. 2008;5(1):23-26. doi:10.5413/mrmc.2008.51.93. 